\title{
Aspartic acid at position 57 of DQ $\beta$ chain does not protect against Type 1 (insulin-dependent) diabetes mellitus in Japanese subjects
}

\author{
K. Yamagata ${ }^{1}$, H. Nakajima ${ }^{1}$, T.Hanafusa ${ }^{1}$, T. Noguchi ${ }^{2}$, A. Miyazaki ${ }^{1}$, J.Miyagawa ${ }^{1}$, M.Sada ${ }^{3}$, H. Amemiya ${ }^{3}$, \\ T. Tanaka ${ }^{2}$, N.Kono ${ }^{1}$ and S. Tarui ${ }^{1}$ \\ ${ }^{1}$ The Second Department of Internal Medicine, \\ ${ }^{2}$ Department of Nutrition and Physiological Chemistry, Osaka University Medical School, and \\ ${ }^{3}$ National Cardiovascular Center, Research Institute, Department of Surgical Research, Osaka, Japan
}

\begin{abstract}
Summary. HLA DQ $\beta$ chain, in particular amino acid at position 57 , has been reported to contribute to susceptibility and resistance to Type 1 (insulin-dependent) diabetes mellitus in Caucasians. Resistance has been proposed to be conferred by aspartic acid at this position. To ascertain the association of HLA DQ $\beta$ and DR $\beta$ genes with Type 1 diabetes in Japanese subjects, ten Japanese Type 1 diabetic patients were investigated at DNA level. Genomic DNA was amplified by polymerase chain reaction, and dot blot analysis was carried out using the amplified DNA with allele specific oligonucleo-
\end{abstract}

tide probes. All patients had aspartic acid at position 57 of at least one of their two $\mathrm{DQ} \beta$ chains, and there was no significant difference of amino acids at the same position of DR $\beta$ chain in patients compared to control subjects. These data indicate that the protective role of aspartic acid at position 57 of DQ $\beta$ chain is less significant in Japanese compared with Caucasian subjects.

Key words: Type 1 (insulin-dependent) diabetes mellitus, HLA-DR, HLA-DQ, polymerase chain reaction.
The association between Type 1 (insulin-dependent) diabetes and particular HLA-DR or DQ types has been reported in Caucasians and Japanese. In Caucasians, the DR4 haplotype in Type 1 diabetic patients is highly associated with DQw3.2 [1] and moreover, the analysis of DNA sequences of Type 1 diabetic patients has revealed the amino acid substitution at position 57 of the $D Q \beta$ chain [2]. The presence of aspartic acid (Asp) at this position of $D Q \beta$ chain is considered to have a protective effect against Type 1 diabetes, and non-aspartic acid (non-Asp), such as alanine, valine and serine, at this position predisposes to Type 1 diabetes. Morel et al. reported that $96 \%$ of Caucasian Type 1 diabetic patients were homozygous non-Asp/non-Asp and 4\% were heterozygous non-Asp/Asp [3]. But, the DQ association with Japanese Type 1 diabetes has not been well studied and the amino acid substitution at this point remains to be solved. Besides, recent serological analysis suggested that the amino acid at position 57 of DR $\beta$ chain may also contribute to susceptibility to Type 1 diabetes in Japanese subjects [4]. In this study, genomic DNA of Japanese Type 1 diabetic patients was amplified by polymerase chain reaction (PCR) and analysed with DQ and DR allele specific oligonucleotide (ASO) probes to determine the amino acids at these two particular positions.

\section{Subjects and methods}

\section{Patients}

Ten Japanese Type 1 diabetic patients were diagnosed according to the criteria of WHO and treated with insulin at the Second Department of Internal Medicine of Osaka University Hospital. Islet cell antibody was positive in eight out of the ten patients. Ten randomly selected control subjects with DR4 and/or DRw9 were chosen from laboratory staff. Informed consent was obtained from all the patients and control subjects. This study was performed in accordance with the principles of the Declaration of Helsinki.

\section{HLA typing}

Serological HLA phenotypes were determined by the NIH standard microlymphocytotoxicity test.

\section{Polymerase chain reaction and dot blot analysis}

Chromosomal DNA was extracted from peripheral blood lymphocytes. One $\mu \mathrm{g}$ of genomic DNA was amplified by polymerase chain reaction [5]. Sixty cycles of denaturation at $95^{\circ} \mathrm{C}$, annealing at $47^{\circ} \mathrm{C}$ and extension at $72^{\circ} \mathrm{C}$ were performed using Thermus thermophilus polymerase (Toyobo Co, Ltd, Osaka, Japan). Reactions were performed under the manufacturer's recommendation except that $10 \%$ dimethyl sulfoxide was added. The amplified DNA showed single band of appropriate length ( $D Q=241$ base pairs, $D R=210$ base pairs) by agarose gel electrophoresis and by Southern blotting of this gel, 


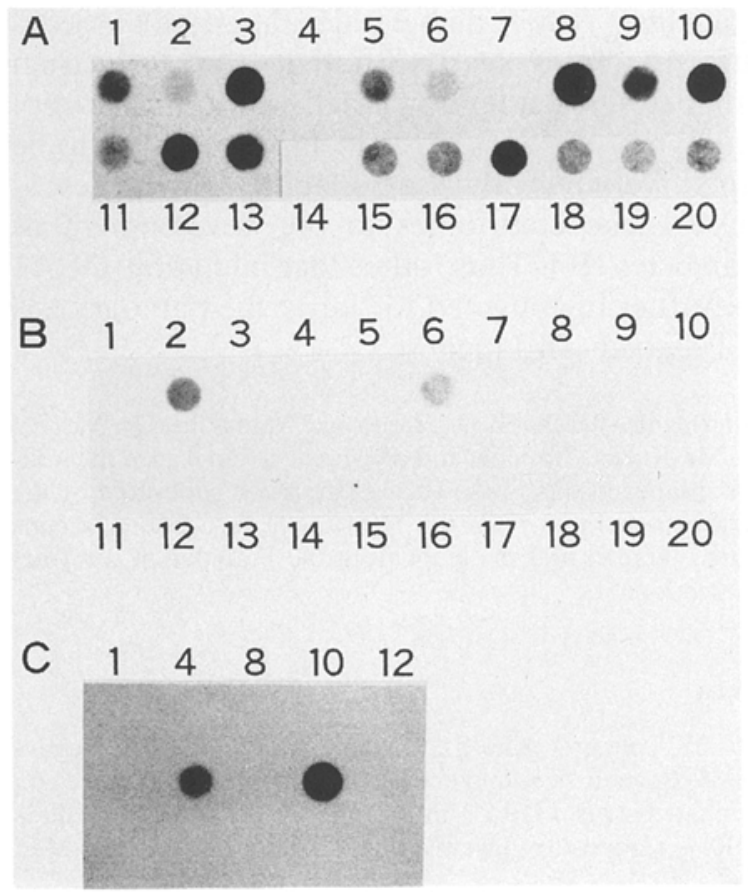

Fig. 1 A-C. Oligonucleotide dot blot analysis. DQ $\beta$ locus amplified DNA was probed with oligonucleotide DQ3.1 (A), DQ3.2 (B) and DQ1.1 (C)

amplified bands selectively hybridized with each respective probe (see below). About $50 \mathrm{ng}$ of each amplified DNA was dot blotted to nylon membrane (Hybond N, Amersham International plc, Amersham, Bucks, UK). After hybridization in $50 \mathrm{mmol} / 1$ Tris. $\mathrm{Cl}$ (pH7.5), $1 \mathrm{~mol} / \mathrm{I} \mathrm{NaCl}$ and $1 \%$ (weight/volume) sodium dodecyl sulfate for $16 \mathrm{~h}$ at $5^{\circ} \mathrm{C}$ below the lowest $\mathrm{Td}\left(\mathrm{Td}=4^{\circ} \mathrm{C}\right.$ per guanine $(\mathrm{G}) /$ cytosine $(\mathrm{C})$ base pair $+2^{\circ} \mathrm{C}$ per adenine(A)/thymine(T) base pair) with allele specific oligonucleotide (ASO) probes, the filters were washed in $6 \times \mathrm{SSC}(1 \times \mathrm{SSC}$ is $0.15 \mathrm{~mol} / 1 \mathrm{NaCl}, 0.015 \mathrm{~mol} / 1$ trisodiumcitrate $)$ at the hybridization temperature for $1 \mathrm{~h}$ and at $\mathrm{Td}$ for $3 \mathrm{~min}$ and autoradiographed.

The DQB primers are DQP1 $\left(5^{\prime}\right.$-GATTTCGTGTACCAGTTTAAGGGC-3' $:$ amino acid positions 6-13) and DQP2 (5'-CCACCTCGTAGTTGTGTCTGCA-3': amino acid positions 79-86) [2]: The DRB primers are DRP1 (5'-CATTTCTTCAACGGGACGGAG-3': amino acid positions 16-22) and DRP2 (5'-AACCCCGTAGTTGTGTCTGCA-3': amino acid positions 79-85) [6]. The probes used in this study were DQ3.1 (5'-GGCCGCCTGACGCCGAG-3'), DQ3.2 (5'GGCCGCCTGCCGCCGAG-3), DQ3.1-26 (5'-CGTGCGTTATGTGACCA-3') and DQ3.3-26 (5'-CGTGCGTCTTGTGACCA-3') for DQw3 specific probes [3]. DQ1.1 (5'-GGCGGCCTGTTGCCGAG$\left.3^{\prime}\right)$, DQ1.2 (5'-GGCGGCCTGATGCCGAG-3'), DQ1.9 (5'-GGCGGCCTGACGCCGAG-3') and DQ1.AZH (5'-GGCGGCCTAGCGCCGAG-3') were used as DQw1 specific probes [3]. The sequence of DQw4 probe was 5'-GGCGGCTTGACGCCGAG-3 ${ }^{\prime}$ [3]. DR4 probes were Dw4 ( $5^{\prime}$-GGCCTGATGCCGAGTACT- $\left.3^{\prime}\right)$ and Dw15 (5'-GGCCTAGCGCCGAGTACT-3') [7]. DR6a probe was identical to Dw4 probe [6]. DR6b probe was $5^{\prime}$-GGCCTGCTGCGGAGCACT-3' [8]. DRw9 specific probe was DR9 a (5'-GGCCTGTCGCCGAGTCC-3') [6]. All probes were $5^{\prime}$-end labelled by $\gamma-\left[{ }^{32} \mathrm{P}\right]$-ATP (370 MBq/ml) using T4 polynucleotide kinase (Toyobo Co, Ltd).

\section{Results}

Serological HLA types of the subjects are shown in the left part of Table $1 . \mathrm{X} /$ - indicates that only $\mathrm{X}$ allele was detected, and it could be regarded as homozygous for
$X$. The minimum frequencies of DR4 and DRw9 in patients were $45 \%$ ( 9 of 20 ) and $20 \%$ ( 4 of 20 ), respectively. All patients tested in this study had DQw3 antigens.

Table 1 also shows the summary of dot blot analysis of DR and DQ haplotypes. Only two of ten DQw3 positive patients had DQw3.2 (Fig.1 A, B) and both were determined as heterozygous non-Asp/Asp. In this study, five out of nine patients $(56 \%)$ were homozygous aspartic acid (Asp/Asp) and four patients (44\%) were heterozygous non-Asp/Asp. Aspartic acid at this particular position was seen in at least one DQB allele in all ten patients. In the control subjects, all but No. 18 were homozygous for aspartic acid. The minimum frequencies of DQw4 and DQw3.3 among Type 1 diabetic patients were $20 \%$ ( 4 of 20 ) and $35 \%$ (7 of 20 ) respectively, as compared to $5 \%$ (1 of 20 ) and $40 \%$ (8 of 20 ) among the healthy control subjects. Two of four serologically DQw1 positive patients (DQw6 is identical to DQw1.2) were proved to be DQw1.1 by dot blot analysis (Fig. 1C), but the other two patients' DNA did not hybridize with any of the four DQw1 probes.

The amino acid at position 57 of DR $\beta$ chain was also investigated. In patients whose phenotypes were both identified by dot blot analysis, the frequencies were $43 \%$ ( 3 of 7 ) for the non-Asp homozygosity, $57 \%$ (4 of 7) for the non-Asp/Asp heterozygosity, and 0\% (0 of 7) for the Asp homozygosity. In the control subjects, the frequencies were $83 \%(5$ of 6$), 17 \%(1$ of 6$)$ and $0 \%(0$ of $6)$, respectively.

Table 1. Serological typing and dot blot analysis of ten Type 1 (insulin-dependent) diabetic patients and ten control subjects

\begin{tabular}{|c|c|c|c|c|c|c|c|}
\hline & \multirow[t]{2}{*}{ No. } & \multicolumn{2}{|c|}{$\begin{array}{l}\text { Serological } \\
\text { typing }\end{array}$} & \multicolumn{2}{|c|}{ Dot blot analysis } & \multirow[b]{2}{*}{ 57-DRB } & \multirow[b]{2}{*}{ 57-DQB } \\
\hline & & $\mathrm{DR}$ & DQ & DR & DQ & & \\
\hline \multicolumn{8}{|l|}{ Patients } \\
\hline & 1 & $2 / 4$ & $1 / 3$ & NT/w15 & $\mathrm{NH} / 3.1$ & $? / \mathrm{NA}$ & ?/A \\
\hline & 2 & $4 /-$ & $3 /-$ & $w 4 / w 15$ & $3.2 / 3.3$ & A $/ \mathrm{NA}$ & $\mathrm{NA} / \mathrm{A}$ \\
\hline & 3 & $4 / 9$ & $3 /-$ & $\mathrm{NH} / 9 \mathrm{a}$ & $3.3 /-$ & $? / \mathrm{NA}$ & $\mathrm{A} /-$ \\
\hline & 4 & $4 / 14$ & $1 / 3$ & $\mathrm{w} 15 / 6 \mathrm{a}$ & $1.1 / 4$ & NA $/ A$ & $\mathrm{NA} / \mathrm{A}$ \\
\hline & 5 & $9 /-$ & $3 /-$ & $9 a /-$ & $3.3 /-$ & $\mathrm{NA}-$ & $\mathrm{A} /-$ \\
\hline & 6 & $4 /-$ & $3 /-$ & w4/w15 & $3.2 / 3.3$ & $\mathrm{~A} / \mathrm{NA}$ & $\mathrm{NA} / \mathrm{A}$ \\
\hline & 7 & $4 /-$ & $3 /-$ & $w 15 /-$ & $4 /-$ & $\mathrm{NA} /-$ & $\mathrm{A} /-$ \\
\hline & 8 & $4 / 6$ & $1 / 3$ & $w 15 / \mathrm{NH}$ & $4 / 3.3$ & NA/? & $\mathrm{A} / \mathrm{A}$ \\
\hline & 9 & $4 / 9$ & $3 /-$ & w15/9a & $3.3 / 4$ & NA/NA & $\mathrm{A} / \mathrm{A}$ \\
\hline & 10 & $4 / 9$ & $3 / 6$ & $\mathrm{w} 4 / 9 \mathrm{a}$ & $3.3 / 1.1$ & $\mathrm{~A} / \mathrm{NA}$ & $\mathrm{A} / \mathrm{NA}$ \\
\hline \multicolumn{8}{|c|}{ Controls } \\
\hline & 11 & $4 / 9$ & $3 /-$ & $\mathrm{w} 15 / 9 \mathrm{a}$ & $3.3 /-$ & NA/NA & $\mathrm{A} /-$ \\
\hline & 12 & $15 / 9$ & $3 / 6$ & NT/9a & $3.1 / 3.3 / 1.9$ & $? / \mathrm{NA}$ & $\mathrm{A} / \mathrm{A}$ \\
\hline & 13 & $4 / 9$ & $3 /-$ & $\mathrm{NH} / 9 \mathrm{a}$ & $3.1 / 3.3$ & $? / \mathrm{NA}$ & $\mathrm{A} / \mathrm{A}$ \\
\hline & 14 & $4 /-$ & NT & w15/- & $4 /-$ & NA $/-$ & $\mathrm{A} /-$ \\
\hline & 15 & $9 /-$ & NT & $9 a /-$ & $3.3 /-$ & $\mathrm{NA} /-$ & $\mathrm{A} /-$ \\
\hline & 16 & $4 / 9$ & $3 /-$ & $\mathrm{w} 15 / 9 \mathrm{a}$ & $3.3 /-$ & NA/NA & $\mathrm{A} /-$ \\
\hline & 17 & $9 /(5)$ & $3 /-$ & $9 \mathrm{a} /(\mathrm{NT})$ & $3.1 / 3.3$ & NA/? & $\mathrm{A} / \mathrm{A}$ \\
\hline & 18 & $7 / 9$ & $2 / 3$ & $\mathrm{NT} / 9 \mathrm{a}$ & $\mathrm{NT} / 3.3$ & $? / \mathrm{NA}$ & $? / \mathrm{A}$ \\
\hline & 19 & $4 / 9$ & $3 /-$ & $w 15 / 9 a$ & $3.3 /-$ & $\mathrm{NA} / \mathrm{NA}$ & $\mathrm{A} /-$ \\
\hline & 20 & $4 / 5$ & $3 /-$ & $w 4 / w 15$ & $3.1 /-$ & $\mathrm{A} / \mathrm{NA}$ & $\mathrm{A} /-$ \\
\hline
\end{tabular}

NT, not tested; NH, not hybridized with any probes; NA, non-Asp; A, Asp; $X /$ - indicates that only $X$ was detected and could be regarded as $\mathrm{X} / \mathrm{X}$; ? indicates that the allele was not detected 


\section{Discussion}

The specific probes in this study enabled us to characterize HLA DR $\beta$ and DQ $\beta$ molecules in detail at DNA level. DQ3.1 and DQ3.2 probes distinguished HLA DQw3.1 and DQw3.3 from DQw3.2. HLA DQw3.3 was differentiated from DQw3.1 with DQ3.1-26 and DQ3.3-26 probes. Characterization of DQw3 was possible at the nucleotide level by the use of these four ASO probes. Similarly, DQw1 was classified as DQw1.1, DQw1.2, DQw1.9 and DQw1.AZH with ASO probes. HLA DR4 is divided into several subtypes by Dw. The nucleotide sequences of Dw4, Dw10, Dw13, Dw14 and DKT2 corresponding to the amino acids 55-61 of the first domain of the $\beta$ chain are identical, but the sequence of Dw15 is different [7]. The amino acid at position 57 of Dw15 is serine and that of the others is aspartic acid. Amino acids at this position of DR6 $b$ and DR9 a are alanine and valine, respectively.

It has been suggested that aspartic acid at position 57 of DQ $\beta$ chain protects against Type 1 diabetes and nonaspartic acid at the same position predisposes Caucasians to Type 1 diabetes $[2,3]$. But the relationship between non-aspartic acid and the disease susceptibility has not yet been reported in Japanese Type 1 diabetic subjects. This study has shown that position 57 of the DQ $\beta$ chain was homozygous for Asp in 56\% and heterozygous for Asp/non-Asp in $44 \%$ of such patients. In the control subjects, all nine subjects whose DNA could be typed were Asp homozygous. These findings have two implications. Firstly, aspartic acid at position 57 of DQ $\beta$ chain does not protect against Type 1 diabetes in Japanese subjects. Secondly, non-Asp at this position may predispose Japanese subjects as well as Caucasians to Type 1 diabetes.

Although Japanese subjects with DR4.1-DQw4 and DRw9-DQw3.3 haplotypes have been reported to be susceptible to Type 1 diabetes [4], the amino acids at position 57 of DQw $4 \beta$ and DQw3.3 $\beta$ chain proved to be aspartic acid in healthy subjects. Since both DR4.1 and DRw9 $\beta$ have non-aspartic acid at this position, the possibility exists that non-Asp in DR $\beta$ may have the same effect as the DQ $\beta$ locus in Japanese subjects, and non-Asp in either DQ $\beta$ or DR $\beta$ may be enough for susceptibility to Type 1 diabetes. However, our data have shown that the frequencies of non-Asp-57 DR homozygotes and heterozygotes were not increased as compared to the healthy control subjects, suggesting that amino acid at position 57 of DR $\beta$ is less important than $D Q \beta$ in Japanese subjects as well as in Caucasians.

DNA from No. 12 hybridized with three probes (3.1, $3.3,1.9)$. These hybridizations were specific, and these sequences were not found in any corresponding loci of DXB, DOB and DPB [9]. So the reason for this discrepancy is unclear at present.

This study has shown that the non-Asp at position 57 of DQ $\beta$ would contribute, at least in part, to susceptibility to Type 1 diabetes in Japanese subjects. On the other hand, aspartic acid at position 57 of DQ $\beta$ does not protect against Type 1 diabetes in Japanese subjects. The latter finding is clearly different from Caucasian Type 1 diabetes. Whether any other position of susceptibility to Type 1 diabetes exists in Japanese is yet to be determined. Very recently, the possibility was suggested that DQA1 gene contributes to the development of Type 1 diabetes [10]. Thus, other loci including DQA1 must be further investigated to clarify the pathogenesis of Type 1 diabetes in Japanese.

Acknowledgements. We thank Dr. Tomoyuki Yamasaki, Dr. Masaru Takenaka, Mr. Kazuya Yamada and Mr. Tatsuya Tanaka for their advice and assistance in this work. This research was supported by the Scientific Research Fund from the Ministry of Education, Science and Culture of Japan and the grant from the Foundation for Total Health Promotion.

\section{References}

1. Nepom BS, Palmer J, Kim SJ, Hansen JA, Holbeck SL, Nepom GT (1986) Specific genomic markers for the HLA-DQ subregion discriminate between DR4 + insulin-dependent diabetes mellitus and DR4 + seropositive juvenile rheumatoid arthritis. J Exp Med 164: $345-350$

2. Todd JA, Bell JI, McDevitt HO (1987) HLA-DQB gene contributes to susceptibility and resistance to insulin-dependent diabetes mellitus. Nature 329: 599-604

3. Morel PA, Dorman JS, Todd JA, McDevitt HO, Trucco M (1988) Aspartic acid at position 57 of the HLA-DQ $\beta$ chain protects against type I diabetes: a family study. Proc Natl Acad Sci USA 85: 8111-8115

4. Aparicio JMR, Wakisaka A, Takada A, Matsuura N, Aizawa M (1988) HLA-DQ system and insulin-dependent diabetes mellitus in Japanese: does it contribute to the development of IDDM as it does in Caucasians? Immunogenetics $28: 240-246$

5. Saiki RK, Gelfand DH, Stoffel S, Scharf SJ, Higuchi R, Horn GT, Mullis KB, Erlich HA (1988) Primer-directed enzymatic amplification of DNA with a thermostable DNA polymerase. Science 239: 487-491

6. Bell JI, Denney D, Foster JL, Belt T, Todd JA, McDevitt HO (1987) Allelic variation in the DR subregion of the human major histocompatibility complex. Proc Natl Acad Sci USA 84: $6234-6238$

7. Gregersen PK, Goyert SM, Song QL, Silver J (1987) Microheterogeneity of HLA-DR4 haplotypes: DNA sequence analysis of LD"KT2" and LD“TAS" haplotypes. Hum Immunol 19: 287-292

8. Tiercy JM, Gorski J, Bétuel H, Freidel AC, Gebuhrer L, Jeannet M, Mach B (1989) DNA typing of DRw6 subtypes: correlation with DRB1 and DRB3 allelic sequences by hybridization with oligonucleotide probes. Hum Immunol 24: 1-14

9. Gustafsson K, Widmark E, Jonsson AK, Servenius B, Sachs DH, Larhammar D, Rask L, Peterson PA (1987) Class II genes of the human major histocompatibility complex. Evolution of the DP region as deduced from nucleotide sequences of the four genes. $J$ Biol Chem 262: 8778-8786

10. Todd JA, Mijovic C, Fletcher J, Jenkins D, Bradwell AR, Barnett AH (1989) Identification of susceptibility loci for insulin-dependent diabetes mellitus by trans-racial gene mapping. Nature 338: 587-589

Received: 19 June 1989

and in revised form: 14 July 1989

Dr. K. Yamagata

The Second Department of Internal Medicine

Osaka University Medical School

1-1-50 Fukushima

Osaka 553, Japan 